\title{
Preparation of Silica Powder in Epoxy Resin Wear-Resistant Coating
}

\author{
Dongdong Zhang, Jihu Wang, Shaoguo Wen*, Pengzhu Wang, Changle Yin, Zhongyan Du \\ College of Chemistry and Chemical Engineering, Shanghai University of Engineering Science, Shanghai, China \\ Email: sdzhangdongdong@163.com, ${ }^{*}$ sg wen@qq.com
}

Received 21 January 2015; accepted 14 February 2015; published 16 February 2015

Copyright (C) 2015 by authors and Scientific Research Publishing Inc.

This work is licensed under the Creative Commons Attribution International License (CC BY). http://creativecommons.org/licenses/by/4.0/

(c) (i) Open Access

\begin{abstract}
Silicon powders possess good thermal stability and rub resistance and can be used as the filler of high temperature wear-resistant coating; it can possess good wettability and dispersibility in the organic polymer by surface modification of silane coupling agent. Organic silicon has good thermal stability, which can modify the frangibility and thermal stability of epoxy resin. A certain proportion of modified silica powder, curing agent and additives were dispersed to modified epoxy resin can compound wear-resistant coating. The results show that: the modification effect can be the best if the dosage of silane coupling agent is $1.5 \%$ of silicon powder. If the methyl triethoxy silane is $50 \mathrm{phr}$ and modified silica powder is $200 \mathrm{phr}$, then various performances of coating tend to be the best.
\end{abstract}

\section{Keywords}

Silane Coupling Agent, Silicon Powder, Epoxy Resin, Organic Silicon, Coating

\section{Introduction}

The frictional loss problem is all over in various departments of national defense construction and national economy. At present, $80 \%$ of machine parts have been damaged due to wear and tear. So coating a layer of wear-resistant coating on the surface of metal mechanical equipment is one of the effective ways to improve the service life of equipments [1]. This experiment aims to develop a kind of wear-resisting coating that is used in severe environment, such as high temperature environment.

The main composition of silicon powder is $\mathrm{SiO}_{2}$, Mohs' scale of hardness is 7, and it is a kind of high-quality wear-resisting filler [2]. The interface properties between the polymer and silicon powder are different, so their compatibility is poor, and silicon powder is hard to evenly disperse in the polymer [3]. Therefore, modification

${ }^{*}$ Corresponding author.

How to cite this paper: Zhang, D.D., Wang, J.H., Wen, S.G., Wang, P.Z., Yin, C.L. and Du, Z.Y. (2015) Preparation of Silica Powder in Epoxy Resin Wear-Resistant Coating. Advances in Materials Physics and Chemistry, 5, 60-66.

http://dx.doi.org/10.4236/ampc.2015.52009 
on the surface of silica powder is becoming very important, and the most effective way is to use silane coupling agent [4] [5]. After the modification, the compatibility and dispersity between modified silica powder and polymer will be greatly improved. The mechanical strength and comprehensive performance has also been greatly improved.

The epoxy resin has strong cohesive force active, because of the existence of epoxy resin, ether and ester keys. Epoxy resin also has strong cohesion of molecular structure compact, so its mechanical properties are better than unsaturated poly vinegar and phenolic resin. But epoxy resin still has defects, such as heat resistance is not high and toughness is not strong, and it has poor weatherability [6].

Organic silicon modified epoxy resin possesses the excellent performance of both organic silicon material and epoxy resin, thus the specific industrial products that are made use of it enjoy great market potential [7]. The in-depth and extensive research on organic silicon modified epoxy resin has started at home and abroad; using organic silicon modified epoxy resin can reduce the internal stress of epoxy resin and increase its high temperature resistance and toughness, etc. [8] [9].

\section{Experimental}

\subsection{Reagent and Instrument}

Silicon powder (400 mesh, size distribution as shown in Figure 1), industrial-grade, Jiangsu Honghao New Materials Co., Ltd.; $\gamma$-(2,3-epoxypropoxy) propytrimethoxy silane (KH560), methyl triethoxy silane, dibutyltin dilaurate, ethyl acetate, epoxy resin(E-44), epoxy curing agent (T31), all were of analytical grade and provided by the Shanghai Pharmaceutical Group Co., Ltd.

\subsection{The Preparation of the Coating}

Mix coupling agent, deionized water and ethanol by volume ratio of 1:1:2, and adjust the $\mathrm{pH}$ value of solution to $\mathrm{pH}=4$, stir magnetically for $12 \mathrm{~min}$ at the same time to fully hydrolyze the coupling agent. Then mix KH560 with dry silica powder by mass fraction of $0.5 \%, 1.0 \%, 1.5 \%, 2 \%$, respectively, pour it into the ball mill, and mill for $30 \mathrm{~min}$. Take out the powder and continue to mill for $30 \mathrm{~min}$ after drying, finally dry it off to get the modified silica powder.

Dissolve the epoxy resin in a certain amount of ethyl acetate solution, pour it into a three-necked flask equipped with dasher, reflux condenser and thermometer, inject the condensate water first, and heat up to 90 degrees, and then add organic silicon, moderate water and catalyst in turn, stir in high speed, keep warm and react for a certain period of time, take it out and filter as a backup.

In the modified epoxy resin solution, add the modified silica powder of different mass fraction, stir in high speed on mechanical stirrer, then add a certain amount of epoxy curing agent (T31), stir evenly, and stand for some time, coat it on the polished and clean tinplate, test its performance after curing at room temperature for some time.

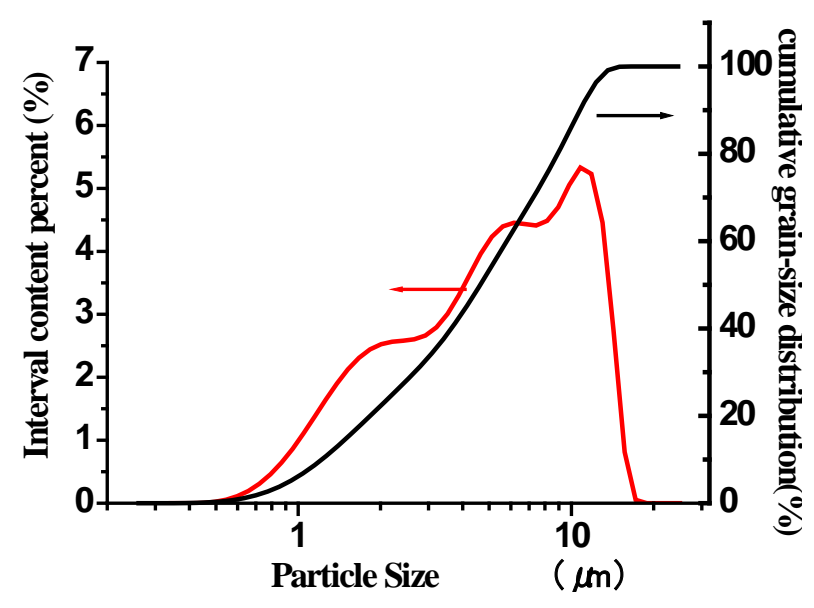

Figure 1. Silicon powder particle size distribution. 


\subsection{Characterization}

Analyze the modified effect of modified silica powder through settling time, oil absorption and activation index. Verify the modification mechanism of modified silica powder and modified epoxide resin through infrared spectrum (FT-IR); analyze the modified effect of modified epoxide resin and the decomposition temperature of wear-resistant paint through thermo gravimetry (TG); analyze the change of modified silica powder surface and wear-resistant paint wear surface through scanning electron microscope (SEM).

\section{Results and Discussion}

\subsection{Particle Size of Silicon Powder}

Using laser particle size analyzer to analyze silicon particle size of powder, the experiment result is shown in Figure 1.

The average particle size of silica powder is $6.43 \mu \mathrm{m}$, the median is $5.68 \mu \mathrm{m}$, and the grain fineness distribution of silicon powder is basically normal distribution.

\subsection{The Effect of Modified Silica Powder}

The modified silica powder is mainly obtained by powder surface coating of modifier and chemical bonds formation (shown in Figure 2), which can increase the dispersibility and wettability of powder in polymer. Therefore, the physical and mechanical properities of the product were improved. The oil absorption value reflects the modified effect; the smaller the oil absorption value of filler in the painting is, the better the filler is.

The test results of modified silica powder sedimentation were shown in Table 1. Compared with the unmodified silica powder, the hydrophobic of modified silica powder has grearly improved. The results can proof that the coupling agent could change the surface properties of ultrafine silica powder. By analyzing the settling time, oil absorption value and activation index, 1.5\% KH560 modified silicon powder is the best.

\subsection{FT-IR Analysis of Silicon Powder}

As shown in Figure 3. After being modified by silane coupling agent, compared with unmodified powder, two obvious organic methylene C-H vibration peaks will appear at $2845.20 \mathrm{~cm}^{-1}, 2920.96 \mathrm{~cm}^{-1}$ of the modified silica powder [6]. $1650.1 \mathrm{~cm}^{-1}$ for C-C stretching vibration, $1870 \mathrm{~cm}^{-1}$ for C-O absorption peak showed that modifier bonded to the surface of the silicon powder [3].

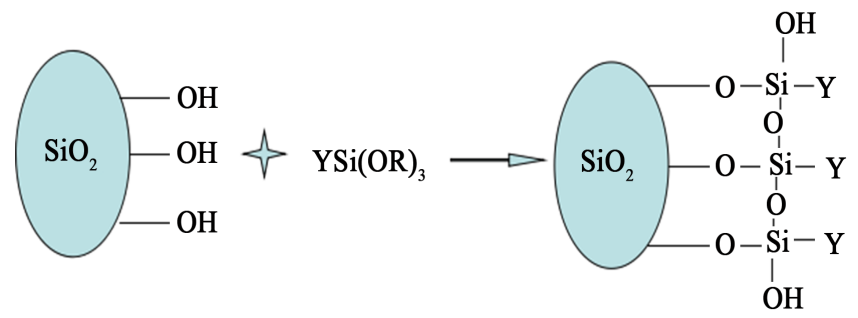

Figure 2. The action mechanism of silane coupling agent on the silicon powder surface.

Table 1. Modified silica powder sedimentation test results.

\begin{tabular}{cccc}
\hline KH560 (\%) & Settling time $(\mathrm{h})$ & Oil absorption (ml/100 g) & Activation index (\%) \\
\hline 0 & 0 & 46 & 0 \\
$0.5 \%$ & $>8$ & 36 & 90.6 \\
$1.0 \%$ & $>8 \mathrm{~h}$ & 32 & 96.1 \\
$1.5 \%$ & $>24 \mathrm{~h}$ & 32 & 94.2
\end{tabular}




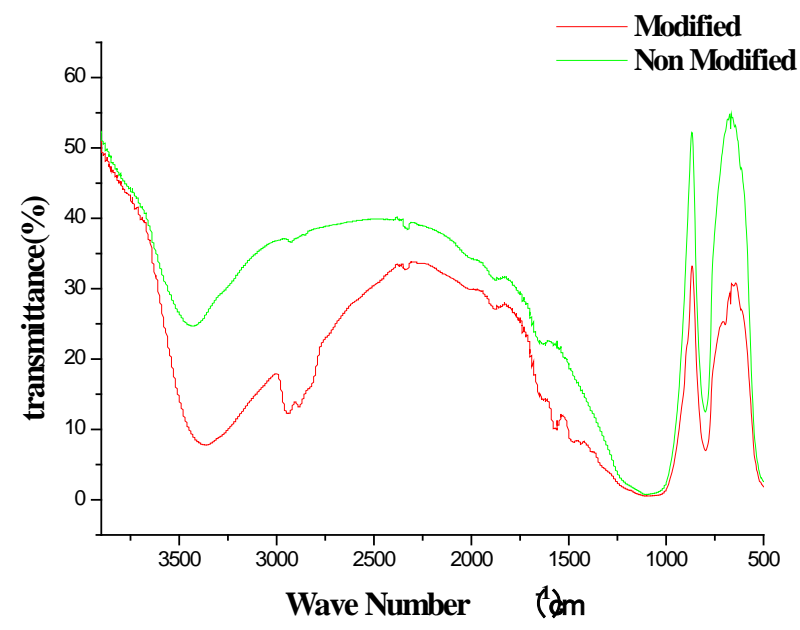

Figure 3. FT-IR of silicon powder before and after modification.

\subsection{Scanning Electron Microscopy (SEM) Analysis of Silicon Powder}

Scanning electron microscopy (SEM) images of modified silica powder are shown in Figure 4.

The agglomerate phenomenon of unmodified silica powder is more serious, the surface is sharp with clear corner angle and uneven surface, while the modified silica powder particles' corner angle is passivated with even surface, showing good modified effect.

\subsection{FT-IR Analysis of Epoxy Resin}

As shown in Figure 5, obvious Si-OH characteristic absorption peak appears in $3447 \mathrm{~cm}^{-1}$ of modified epoxy resin, whose area is smaller than that of pure epoxy resin, showing the consumption of hydroxy, that is, the hydrolysate of methyl triethoxy silane reacts with the hydroxy in epoxy resin. At the same time, the characteristic peaks in $1181 \mathrm{~cm}^{-1}, 1031 \mathrm{~cm}^{-1}$ and $827 \mathrm{~cm}^{-1}$ show the emergence of Si-O-C, Si-O-Si and Si-O-Si perssad, which confirms that the methyl triethoxy silane modifies the epoxy resin smoothly [10] [11].

\subsection{Thermal Stability Analysis of Epoxy Resin}

TG spectra before and after the modification of epoxy resin are shown in Figure 6.

The temperature under each mass loss rate of modified epoxy resin is a little higher than that of the pure epoxy resin, because the hydrolysate of methyl triethoxy silane, namely the Si-O chain with higher relative bond energy, is introduced into the epoxy main chain, and thus enhancing the bond energy of main chain and improving its heat-resistant quality. Modified epoxy resin decomposition temperature is $371^{\circ} \mathrm{C}$, significantly higher than the unmodified epoxy resin. Modification of epoxy resin shows good temperature resistance.

\subsection{The Wear Resistance of Coating Test}

The relationship between the wear performance of coatings and the dosage of silicon powder after using film abrasion tester wearing 100 r, 300 r, and $500 \mathrm{r}$ is shown in Figure 7.

As the wear-resisting filler, silica powder is the inorganic inert filler and cannot participate in the curing reaction of coating, it can lower the curing shrinkage rate; the modified silica powder combines closely with matrix resin, forming the tight protective layer, improving the cohesion and abrasion resistance of painting. When the dosage of modified silicon powder is $200 \mathrm{phr}$, the abrasion loss of coating is the minimum with the best abrasive resistance.

\subsection{SEM Analysis of Wear Resistant Coating}

When the dosage of unmodified silica powder (a) and the modified silica powder (b) is 200 phr, micro performance of coating is shown in Figure 8. 


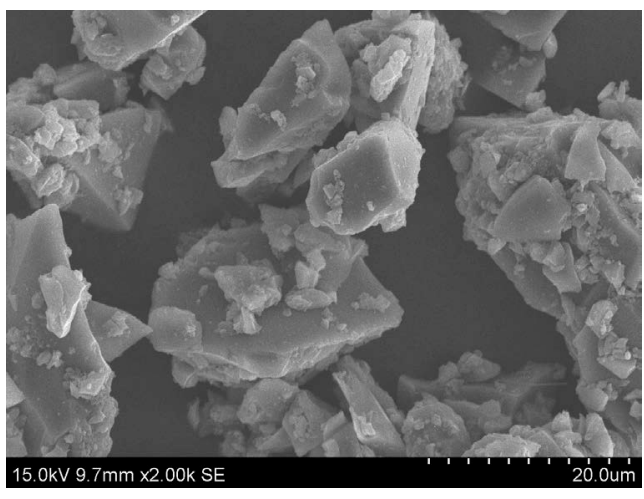

(a)

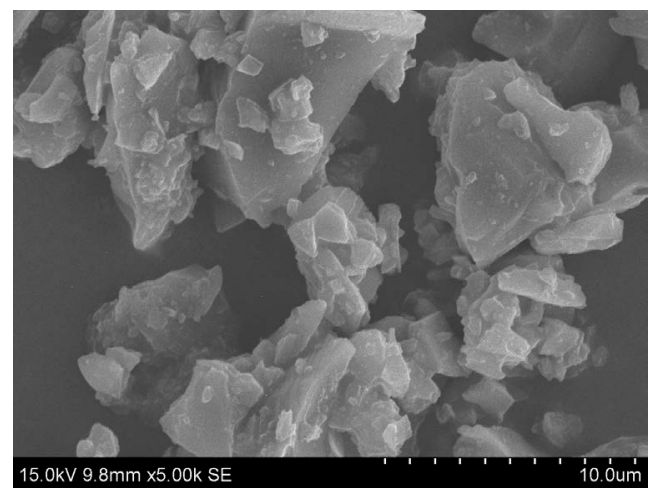

(b)

Figure 4. SEM images of silicon powder before (a) and after (b) modification.

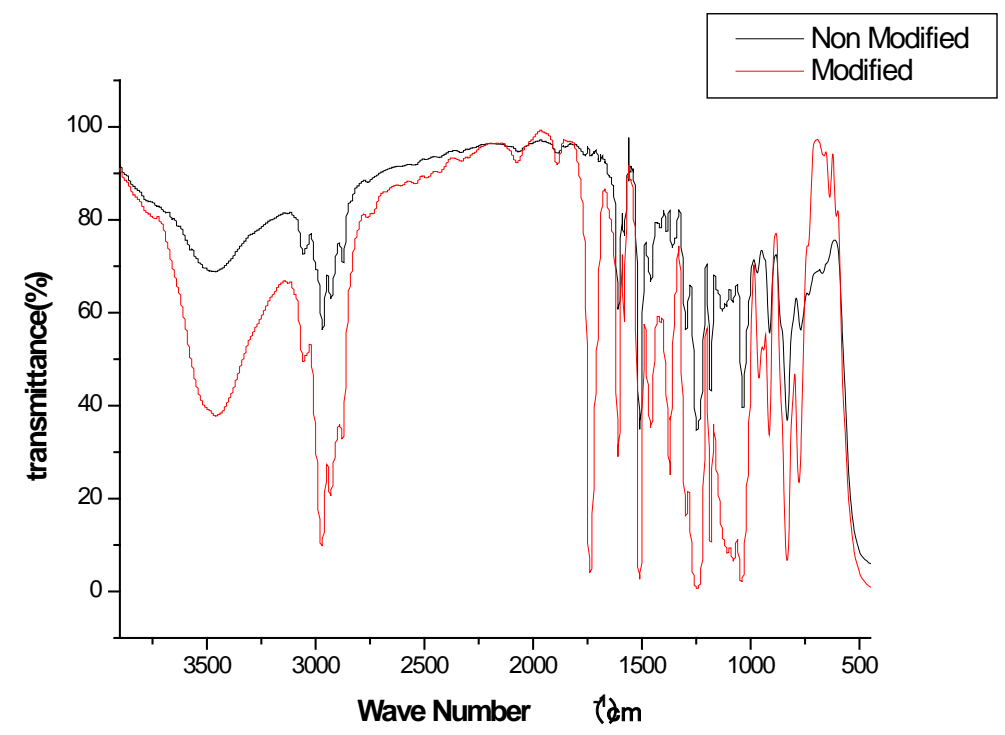

Figure 5. FT-IR of epoxy resin before and after modification.

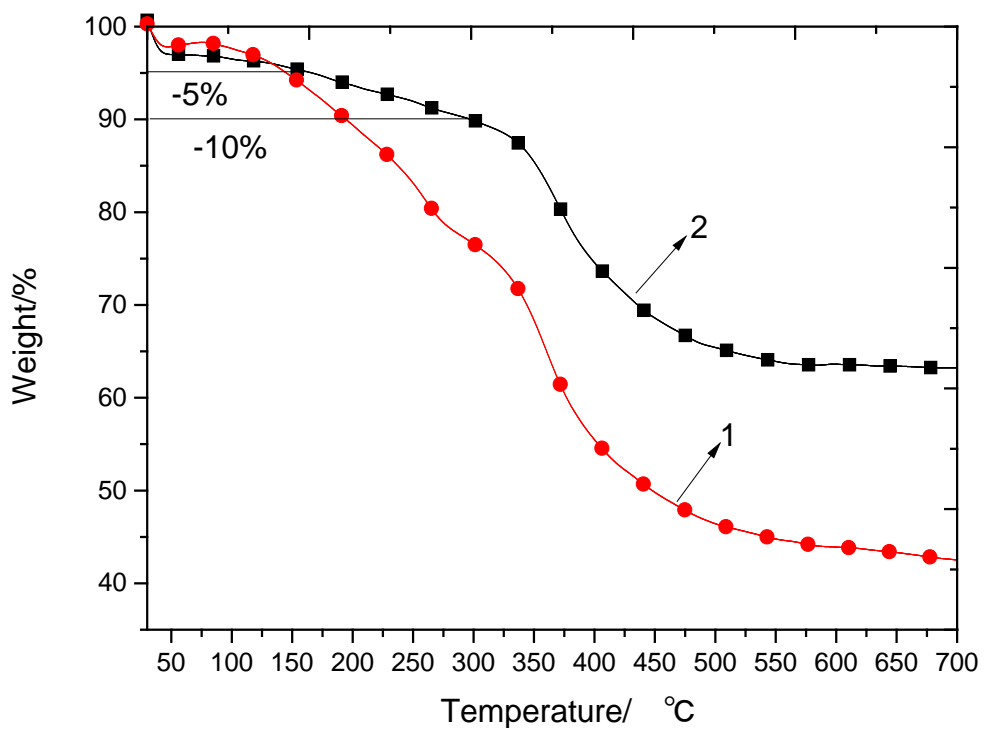

Figure 6. TG spectra before and after the modification of epoxy resin. 


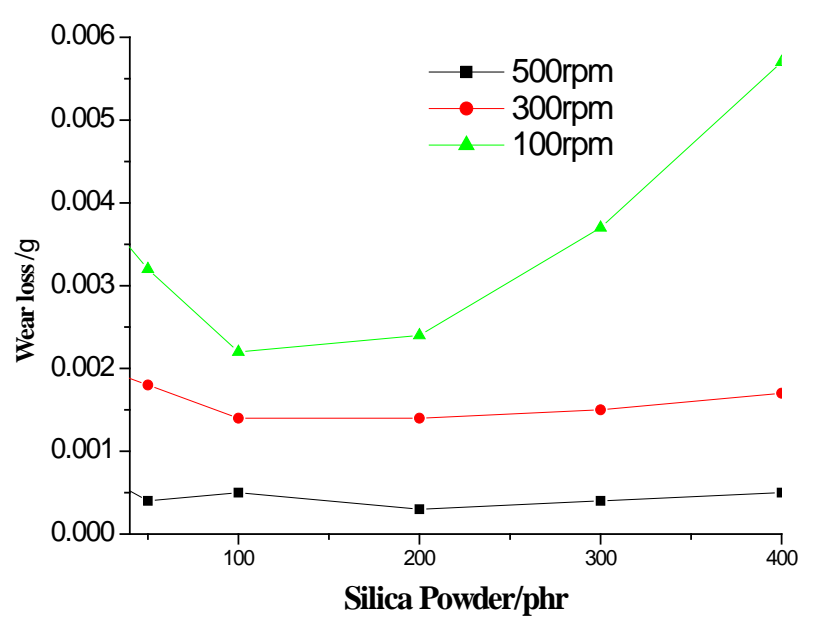

Figure 7. The wear resistance of coating test.

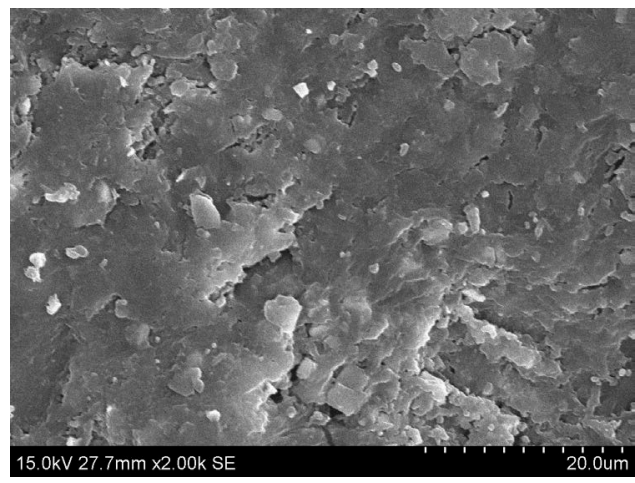

(a)

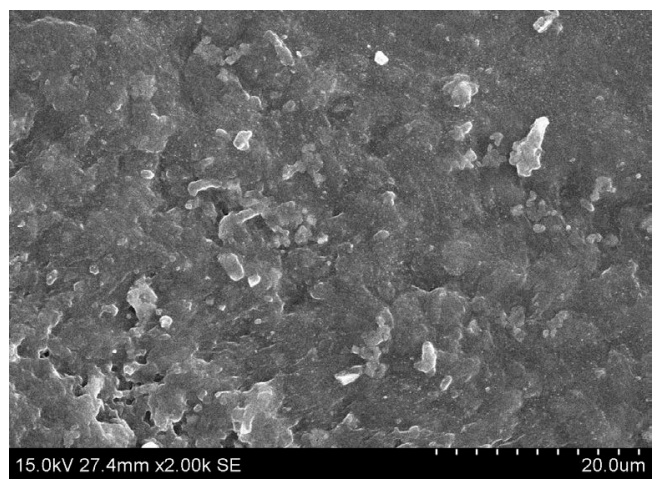

(b)

Figure 8. SEM analysis of wear resistant coating.

When adding the filler to a certain amount, the hole formed by the filler can be filled fully by the binding agent, and the coating possesses the best erosive wear resistance. In addition, the modification of epoxy resin improves the bonding strength of adhesive bonding to ceramic particles, thus the ceramic particles are more difficult to fall off from the adhesive bonding, thereby playing the leading role in wear resistance. It can be seen from Figure 8 that while the ceramic particle has been broken due to abrasive impact, it is difficult for particles to fall off from the adhesive bonding because the resin has enough bonding strength for particles, further improving the erosion wear resistance of coating.

\section{Conclusions}

Silica powder can possess good wettability and dispersibility in the organic polymer by surface modification of silane coupling agent. Organic silicon can modify the frangibility and thermal stability of epoxy resin. Adding a certain proportion of modified silica powder, curing agent and additives to modified epoxy resin can compound wear-resistant coating. The coating has good wear resistance.

The modification effect can be the best if the dosage of silane coupling agent is $1.5 \%$ of silicon powder. If the methyl triethoxy silane is $50 \mathrm{phr}$ and modified silica powder is $200 \mathrm{phr}$, then various performances of painting tend to be the best.

\section{References}

[1] Xu, P., Lin, C.X., Zhou, C.Y. and Yi, X.P. (2014) Wear and Corrosion Resistance of Laser Cladding AISI 304 Stainless Steel/ $\mathrm{Al}_{2} \mathrm{O}_{3}$ Composite Coatings. Surface and Coatings Technology, 238, 9-14. http://dx.doi.org/10.1016/j.surfcoat.2013.10.028 
[2] Zhao, J., Milanova, M., Warmoeskerken, M.M.C.G. and Dutschk, V. (2012) Surface Modification of TiO $\mathrm{N}_{2} \mathrm{Nano}^{\mathrm{Particles}}$ with Silane Coupling Agents. Colloids and Surfaces A: Physicochemical and Engineering Aspects, 413, 273-279. http://dx.doi.org/10.1016/j.colsurfa.2011.11.033

[3] Liu, W., Xie, Z.P. and Jia, C. (2012) Surface Modification of Ceramic Powders by Titanate Coupling Agent for Injection Molding Using Partially Water Soluble Binder System. Journal of the European Ceramic Society, 32, 1001-1006. http://dx.doi.org/10.1016/j.jeurceramsoc.2011.11.017

[4] Wang, Z.H., Huang, Z.F., Chen, F., Shen, Q. and Zhang, L.M. (2014) Surface Passivation of Nanocrystalline Silicon Powder Derived from Cryomilling. Journal of Wuhan University of Technology-Mater Sci. Ed., 29, 65-69. http://dx.doi.org/10.1007/s11595-014-0868-9

[5] Lou, M.Y., Wang, D.P., Huang, W.H., Chen, D. and Liu, B. (2006) Effect of Silane-Coupling Agents on Synthesis and Character of Core-Shell $\mathrm{SiO}_{2}$ Magnetic Microspheres. Journal of Magnetism and Magnetic Materials, 305, 83-90. http://dx.doi.org/10.1016/j.jmmm.2005.11.038

[6] Li, H.Y, Wang, R.G, Hu, H.L. and Liu, W.B. (2008) Surface Modification of Self-Healing Poly (Urea-Formaldehyde) Microcapsules Using Silane-Coupling Agent. Applied Surface Science, 255, 1894-1900. http://dx.doi.org/10.1016/j.apsusc.2008.06.170

[7] Hsiue, G.-H., Wei, H.-F., Shiao, S.-J., Kuo, W.-J. and Sha, Y.-A. (2001) Chemical Modification of Dicyclopentadiene Based Epoxy Resins to Improve Compaibility and Thermal Properties. Polymer Degradation and Stability, 73, 309318. http://dx.doi.org/10.1016/S0141-3910(01)00092-1

[8] Liu, K.X., Liu, M., Hou, L.H, et al. (2007) The Research Progress of Organic Silicone Modified Epoxy Resin. Shandong Chemical Industry, 37, 11-13.

[9] Lakshmi, R.V., Bharathidasan, T. and Basu, B.J. (2011) Superhydrophobic Sol-Gel Nanocomposite Coatings with Enhanced Hardness. Applied Surface Science, 257, 10421-10426. http://dx.doi.org/10.1016/j.apsusc.2011.06.122

[10] Adam, F., Osman, H. and Hello, K.M. (2009) The Immobilization of 3-(Chloropropyl) Triethoxysilane onto Silica by a Simple One-Pot Synthesis. Journal of Colloid and Interface Science, 331, 143-147. http://dx.doi.org/10.1016/j.jcis.2008.11.048

[11] Wei, B.G., Chang, Q., Bao, C.X., Dai, L., Zhang, G.Z. and Wu, F.P. (2013) Surface Modification of Filter Medium Particles with Silane Coupling Agent KH550. Colloids and Surfaces A: Physicochemical and Engineering Aspects, 434, 276-280.http://dx.doi.org/10.1016/j.colsurfa.2013.05.069 
Scientific Research Publishing (SCIRP) is one of the largest Open Access journal publishers. It is currently publishing more than 200 open access, online, peer-reviewed journals covering a wide range of academic disciplines. SCIRP serves the worldwide academic communities and contributes to the progress and application of science with its publication.

Other selected journals from SCIRP are listed as below. Submit your manuscript to us via either submit@scirp.org or Online Submission Portal.
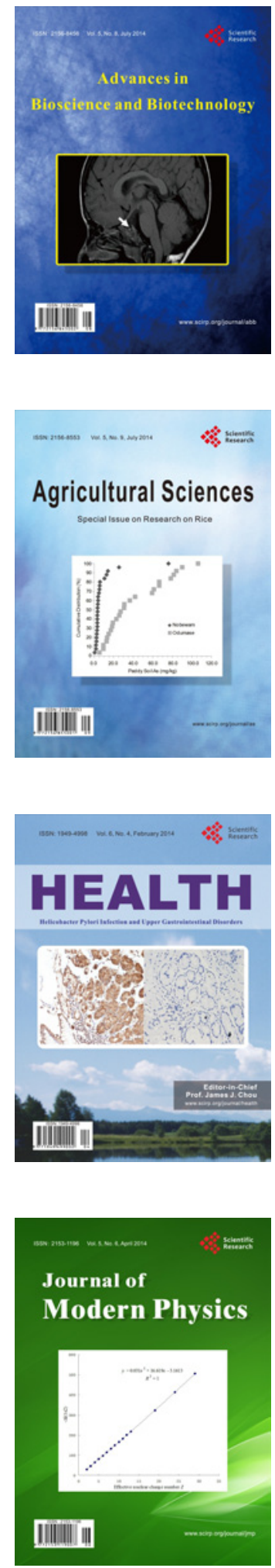
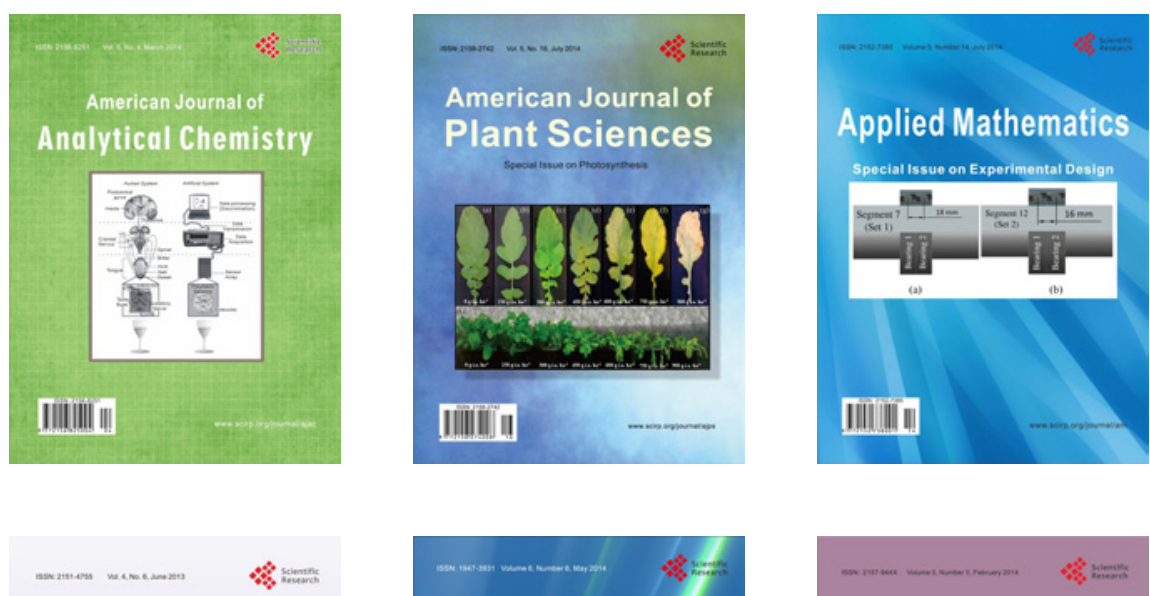

Creative Education
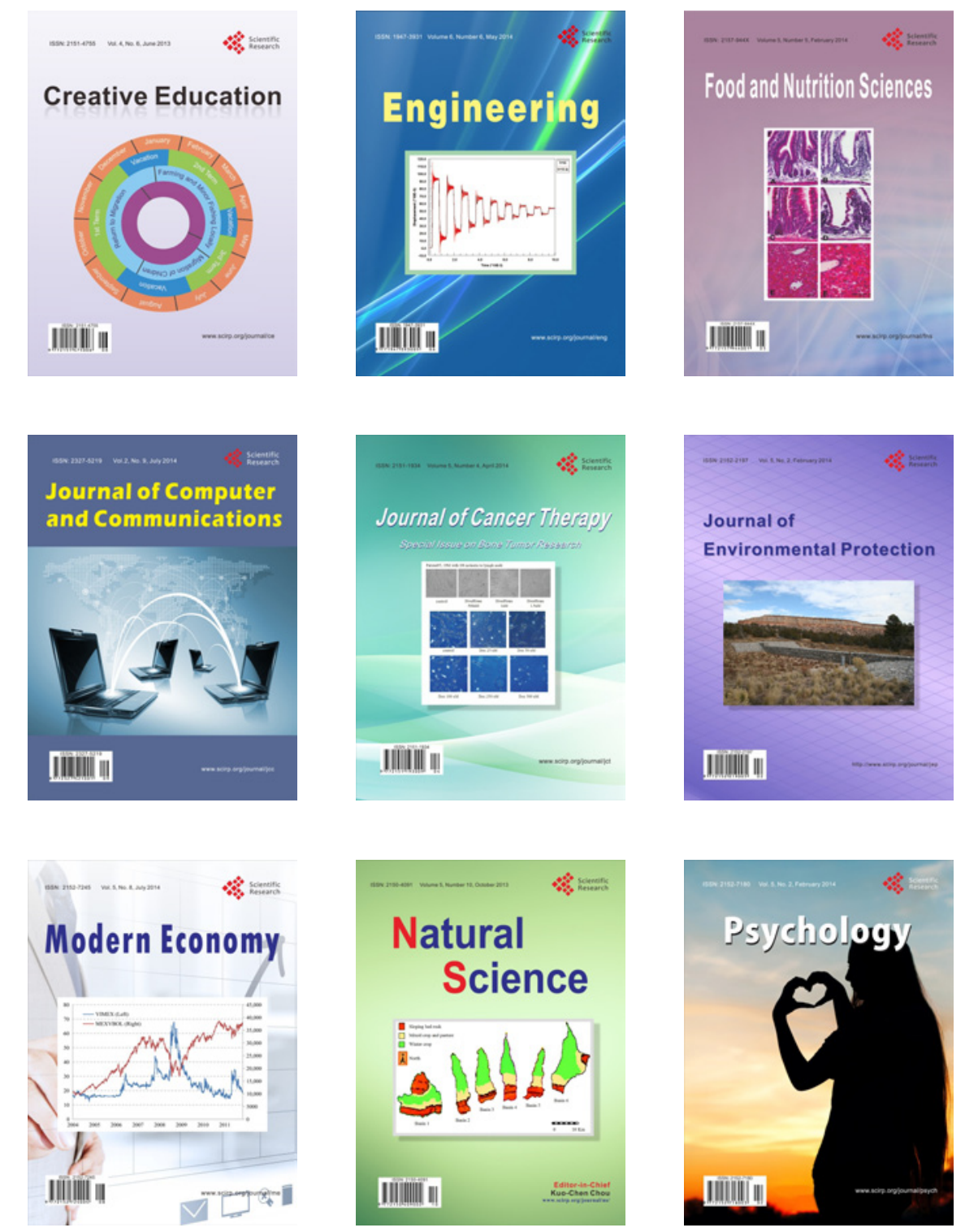